\title{
O CÓDIGO CULTURAL DA LINGUAGEM COMO “MARCA" DA IDENTIDADE TERRITORIAL NO VALE DO TAQUARI/RS
}

\author{
Juliana Cristina Franz \\ Universidade Federal de Santa Maria \\ Doutora pelo Programa de Pós-Graduação em Geografia, Santa Maria, RS, Brasil \\ julianafranz@gmail.com \\ Meri Lourdes Bezzi \\ Universidade Federal de Santa Maria \\ Professora no Programa de Pós-Graduação em Geografia, Santa Maria, RS, Brasil \\ meribezzi@yahoo.com.br
}

\begin{abstract}
RESUMO
O presente artigo objetiva entender os processos contraditórios e combinados, a manutenção e, simultaneamente, as transformações de características do código cultural da linguagem dos imigrantes e descendentes alemães que se instalaram historicamente e se reproduzem atualmente no Vale do Taquari/RS. A operacionalização da pesquisa, ocorreu primeiramente a partir de uma revisão teórica e histórica do processo de imigração e colonização alemã no Vale do Taquari/RS para posteriormente realizar a pesquisa empírica que visou, através de entrevistas, construir o conhecimento em torno da problemática central da pesquisa. Na região de estudo identificou-se uma expressividade no uso dos dialetos alemães no cotidiano, principalmente nos ambientes familiares, sendo mais presente na relação com as pessoas idosas e nas áreas rurais. Essa presença se restringe à língua falada, uma vez que não foi identificado domínio, por parte da comunidade, da escrita em alemão. A transmissão de significados da cultura ocorre com o uso da linguagem, principalmente da oralidade, pois o saber-fazer é transmitido entre as gerações por intermédio dela. A língua, além de ser um veículo de aproximação entre seus pares, também se configura como um elemento diferenciador, configurando-se como uma fronteira linguística, diferenciando o pertencimento a um grupo ou não.
\end{abstract}

Palavras-chave: Código Cultural. Linguagem. Geografia Cultural. Território.

\section{THE CULTURAL CODE OF LANGUAGE AS A "BRAND" OF TERRITORIAL IDENTITY IN THE VALE DO TAQUARI/RS}

\begin{abstract}
This article aims to understand the contradictory and combined processes, the maintenance and, simultaneously, the transformations of characteristics of the cultural code of the language of German immigrants and descendants who settled historically and are currently reproducing in the Vale do Taquari/RS. The operationalization of the research took place first from a theoretical and historical review of the process of German immigration and colonization in the Vale do Taquari/RS to later carry out empirical research that aimed, through interviews, to build knowledge around the central problem of search. In the study region, an expressiveness in the use of German dialects in everyday life was identified, mainly in family environments, being more present in the relationship with the elderly and in rural areas. This presence is restricted to the spoken language, since no dominance by the community of writing in German has been identified. The transmission of cultural meanings occurs with the use of language, especially orality, as know-how is transmitted between generations through it. The language, besides being a vehicle of approximation between its peers, is also configured as a differentiating element, configuring itself as a linguistic frontier, differentiating belonging to a group or not.
\end{abstract}

Keywords: Cultural Code. Language. Cultural Geography. Territory.

\section{INTTRODUÇÃO}

A pesquisa se insere na perspectiva da Geografia Cultural, a qual, a partir de 1980, agrega novas interpretações e preocupações e, como resultado, reformula-se e passa a denominar-se Geografia Cultural Renovada. Neste entendimento, a cultura está atrelada à compreensão dos significados criados e

$\begin{array}{lllll}\text { Caminhos de Geografia } & \text { Uberlândia-MG } & \text { v. } 21, \text { n. } 77 & \text { Out/2020 } & \text { p. 180-192 Página } 180\end{array}$


recriados pelos diversos grupos sociais no que concerne às diferentes esferas da vida em suas espacialidades e historicidades específicas. Através deste viés interpretativo, a cultura não é determinante, mas se constitui em um contexto, ou seja, ela é reflexo, meio e condição da existência e reprodução dos diferentes grupos sociais (CORRÊA; ROSENDAHL, 2012).

Neste sentido, Cosgrove (2003, p. 103) afirma que "toda atividade humana é ao mesmo tempo material e simbólica, produção e comunicação". Dessa forma, deve-se atentar para os múltiplos significados expressos pelos símbolos culturais. Esta análise pode ser realizada sobre diversos aspectos da espacialidade humana, considerando as distintas temporalidades e escalas espaciais.

O presente estudo contempla a escala local e regional como recorte de análise, com enfoque no processo de imigração e colonização alemã na região do Vale do Taquari, esta região está localizada na porção centro-leste do estado do Rio Grande do Sul e historicamente é compreendida na "Colônia Velha". Destaca-se que, no estado gaúcho, o ano de 1824 marca o início do processo de imigração e colonização alemã, estando diretamente relacionado ao processo histórico europeu do século XIX.

A ocupação territorial empreendida pelos imigrantes revela uma adaptação ao novo habitat e, com algumas diferenciações, mantém elementos da cultura de origem dos imigrantes, conformando um sistema cultural peculiar que ainda persiste na atualidade. Considerando a reprodução do processo colonizador, a vida cotidiana nas colônias constitui-se também por saberes, fazeres e valores que foram sendo reproduzidos, migrando com os grupos sociais, produzindo e reproduzindo demandas e necessidades que gradativamente vão sendo preenchidas pelas ações e inventividades de seus elementos territorializados, desde o início do processo migratório, os imigrantes se defrontaram com a necessidade de adaptar seus saberes, fazeres e práticas à nova terra, agregando valores até então desconhecidos por eles.

Diante do exposto, o objetivo que se visa responder neste trabalho é: entender os processos contraditórios e combinados, a manutenção e, simultaneamente, as transformações de características do código cultural da linguagem dos imigrantes e descendentes alemães que se instalaram historicamente e se reproduzem atualmente no Vale do Taquari.

A operacionalização da pesquisa, ocorreu primeiramente a partir de uma revisão teórica e histórica do processo de imigração e colonização alemã no Rio Grande do Sul e mais especificamente no Vale do Taquari para posteriormente realizar a pesquisa empírica que visou, através de fontes primárias, construir o conhecimento em torno da problemática central da pesquisa. Esta relação entre a pesquisa bibliográfica e a empírica é importante no sentido de que a primeira auxilia o entendimento do tema e as diferentes abordagens sobre ele, bem como a definição de sujeitos relevantes para a fase de entrevistas, para a obtenção de diferentes pontos de vistas e reflexões sobre a temática abordada.

Dessa forma, a orientação qualitativa da metodologia foi operacionalizada através do trabalho de campo a partir da realização das entrevistas. São muitas as técnicas de coleta de dados abrangidas pelos estudos qualitativos, mas a entrevista é, dentre todas, a mais difundida e prestigiada.

A modalidade de entrevistas adotada nesta pesquisa é a semiestruturada, a qual é dirigida por um roteiro que abarca perguntas elaboradas previamente, mas não necessariamente se restringe a estas. $\mathrm{O}$ pesquisador dispõe de liberdade para formular novas questões, caso lhe pareça apropriado. Nesse tipo de entrevista, ocorre um maior aproveitamento do conhecimento e das percepções dos entrevistados, pois cada resposta pode encontrar um grande campo de possibilidades a serem investigadas, sugerindo novas questões não previstas pelo pesquisador quando formulou o roteiro (MATOS; PESSÔA, 2009; SILVA; MENDES, 2013).

Desse modo, em termos operacionais, realizaram-se entrevistas amparadas em roteiros estruturados por pautas, direcionadas aos sujeitos compreendidos como "elementos-chave" para a pesquisa, pertencentes a dois grupos, a saber: o primeiro, os representantes municipais (membros das Secretarias de Cultura dos dez municípios pesquisados), e o segundo, os membros da comunidade (pessoas indicadas pelo primeiro grupo, geralmente idosos).

\section{PROCESSO HISTÓRICO DE IMIGRAÇÃO E COLONIZAÇÃO ALEMÃ NO VALE DO TAQUARI}

A imigração e a colonização alemã iniciaram no século XIX, e os imigrantes colonos que se estabeleceram na Província do Rio Grande do Sul localizaram-se nas áreas de florestas entre o Litoral e o Planalto e foram imprimindo nessas regiões as características das pequenas propriedades policultoras de caráter familiar. Ainda, devido ao isolamento nos primeiros anos de instalação, passaram a desenvolver um comércio de pequena escala local (SEYFERTH, 1974). 
A colonização que ocorreu no Rio Grande do Sul é denominada de colonização "alemã", e os colonos são denominados de "colonos alemães". Tomando como referência Seyferth (1974), a qual expõe que, para a compreensão destas categorias, o critério utilizado não é político, consideram-se os povos falantes da língua alemã ou de seus dialetos, juntamente com a questão territorial da localização dos ducados (Estados) que, posteriormente, viriam a conformar a Alemanha

A ocupação territorial empreendida pelos imigrantes revela uma adaptação ao novo habitat e, com algumas diferenciações, mantém elementos da cultura de origem dos imigrantes, conformando um sistema cultural peculiar que ainda persiste na atualidade. (SEYFERTH, 2015).

Considerando a reprodução do processo colonizador, a vida cotidiana nas colônias constitui-se também por saberes, fazeres e valores que foram sendo reproduzidos, migrando com os grupos sociais, produzindo e reproduzindo demandas e necessidades que gradativamente vão sendo preenchidas pelas ações e inventividades de seus elementos territorializados.

Nesta perspectiva, a pesquisa buscou o aprofundamento do recorte territorial onde a colonização alemã foi mais densa no Vale do Taquari, se destacando a região central do Vale do Taquari, pois é nela onde se registra a presença significativa de imigrantes alemães, a partir da segunda metade do século XIX. Este recorte territorial é composto por dez unidades territoriais: Arroio do Meio, Colinas, Estrela, Forquetinha, Lajeado, Marques de Souza, Poço das Antas, Santa Clara do Sul, Teutônia e Westfália (Figura 1).

Enfatiza-se, também, que a região norte do Vale do Taquari foi majoritariamente colonizada pela imigração italiana, e a região sul recebeu os imigrantes açorianos. Essa configuração territorial foi estabelecida com base nas informações bibliográficas sobre as formações históricas das colônias, em conjunto com os dados coletados junto às prefeituras municipais.

Figura 1 - Vale do Taquari (RS): Mapa da colonização nos municípios, 2018.
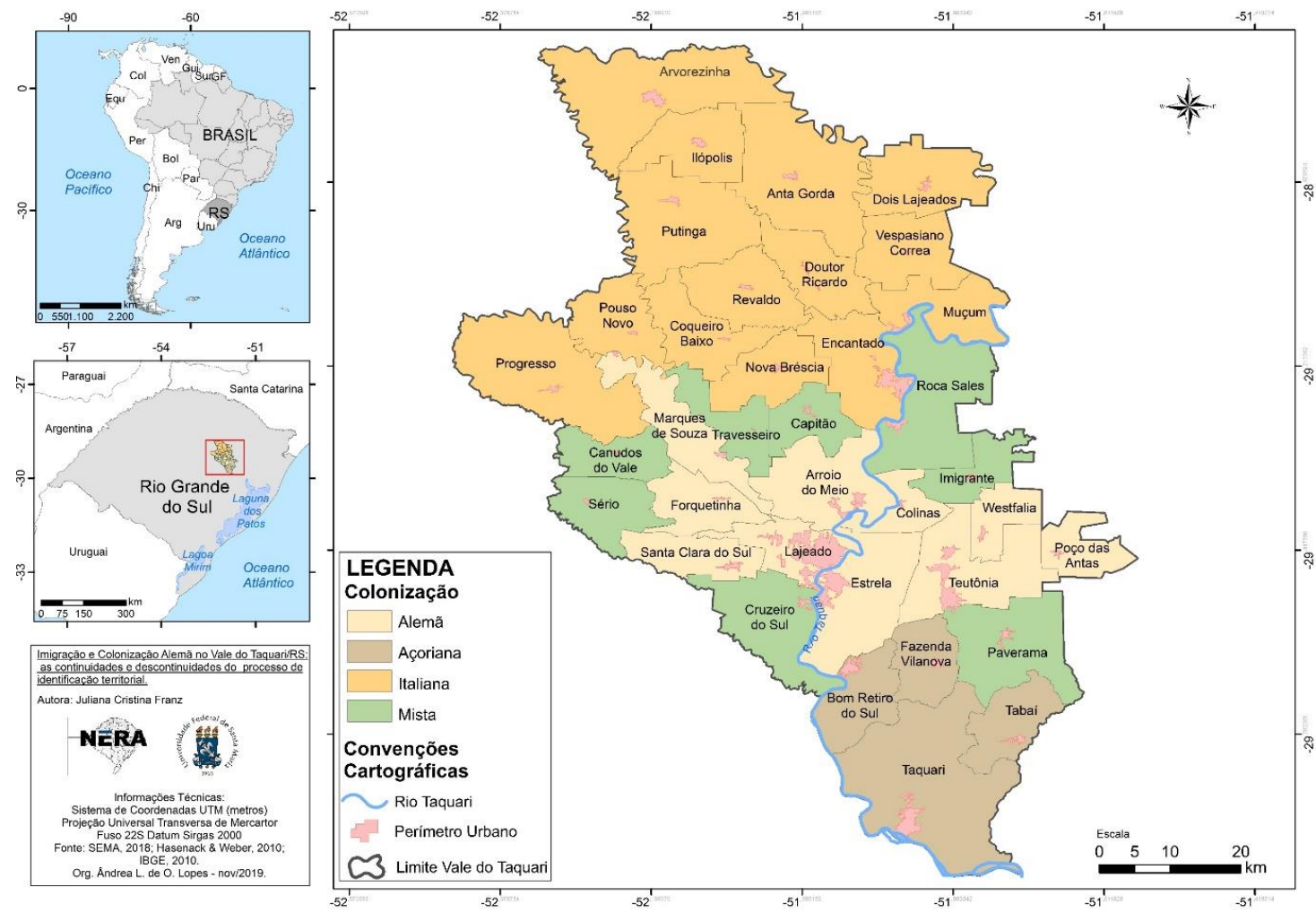

Fonte - SEMA, 2018; HASENACK; WEBER, 2010; IBGE, 2010.

\section{CONCEITUAÇÃO TEÓRICA DOS CÓDIGOS CULTURAIS}

Os códigos culturais são compreendidos como um sistema de símbolos representados por categorias separadas, mas que conjuntamente permitem a interpretação da cultura no espaço. Também permitem entender a transmissão das características culturais entre as gerações. Sucintamente, os códigos culturais expressam a materialidade e a imaterialidade da cultura manifestada na paisagem.

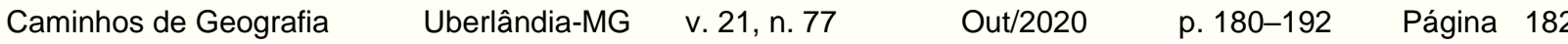


A produção e reprodução da vida material são, necessariamente, uma arte coletiva, mediada na consciência e sustentada através de códigos de comunicação. Esta última é produção simbólica. Tais códigos incluem não apenas a linguagem em seu sentido formal, mas também o gesto, o vestuário, a conduta pessoal e social, a música, pintura, a dança, o ritual, a cerimônia e as construções. Mesmo essa lista não esgota a série de produções simbólicas através das quais mantemos o nosso mundo vivido, porque toda atividade humana é, ao mesmo tempo, material e simbólica, produção e comunicação. Essa apropriação simbólica do mundo produz estilos de vida (genres de vie) distintos e paisagens distintas, que são histórica e geograficamente específicos. A tarefa da geografia cultural é apreender e compreender essa dimensão da interação humana com a natureza e seu papel na ordenação do espaço (COSGROVE, 2007, p. 103).

Neste contexto, Wagner e Mikessel (2003) complementam que a cultura resulta da capacidade humana de se comunicar entre si por intermédio de símbolos/códigos. Cosgrove e Jackson (2003) expõem que a cultura é o meio pelo qual a mudança social é experenciada, contestada e constituída. E, com base em Hall (1999), considera-se que a cultura é o meio através do qual as pessoas transformam o fenômeno cotidiano do mundo material em um mundo de símbolos significativos, ao qual atrelam valores e dão sentido.

Além da terminologia códigos culturais, para apresentar a simbologia representativa da cultura, há outros termos em uso nas Ciências Sociais, como signos, símbolos, marcadores identitários ou territoriais, entre outros, para compreender a (i)materialidade da cultura no espaço.

Claval (1999), ao tratar dos códigos, expõe que todo elemento cultural que permite sua visualização na paisagem é um código cultural material, e aquele que não possibilita tal visualização constitui-se em um código cultural imaterial. Brum Neto (2007, p. 44) afirma que os códigos culturais "[...] constituem-se na simbologia responsável pela visibilidade da cultura e, também, pela sua transmissão".

Os atributos culturais se expressam nas paisagens por intermédio do estilo arquitetônico das habitações, da gastronomia, da arte, dos trajes típicos, da religião, das festividades e suas músicas e danças, entre outros elementos, e que, mesmo não sendo visíveis, influenciam a materialização da cultura no espaço. Entre estes pode-se destacar como códigos culturais os valores, as ideologias e as convenções (CAETANO; BEZZI, 2011; BRUM NETO, 2007).

Brum Neto (2012) também afirma que os códigos permitem identificar as similaridades e as diferenças entre grupos, uma vez que retratam aspectos da cultura. Por sua vez, Hall (2003) concebe as marcas simbólicas como elementos diferenciadores sociais entre os distintos grupos sociais.

A tarefa de analisar os aspectos simbólicos é complexa, pois devem-se considerar tanto os aspectos visíveis da cultura como os subjetivos, que envolvem o plano das ações, dos pensamentos e dos sentimentos, e estes são difíceis de ser identificados, mensurados e analisados. Brum Neto (2012, p. 93) destaca a importância da "análise da (i)materialidade para a compreensão da cultura, por ser uma dimensão repleta de simbologias e significados".

Com base nas conceituações supracitadas, os códigos culturais podem ser entendidos como elementos representativos da cultura. Eles permitem a análise da cultura em categorias, para que se possa identificar, comparar e analisar seus componentes, e configuram-se como convenções simbólicas que são partilhadas por um determinado grupo social. Estes códigos também se inter-relacionam, uma vez que no seu conjunto compõem a cultura (BRUM NETO, 2012).

A cultura, mediada pelos códigos é representada e materializada no espaço, originando formas típicas, passíveis de reconhecimento pelos demais grupos sociais, ou seja, criando processos de identificação. Decifrar e interpretar os códigos significa entender a dinâmica da cultura em questão, os valores e crenças que orientam as atitudes e ações. Estas, por sua vez, são repetidas como um padrão orientador comum (BRUM NETO, 2012, p. 94)

Claval (1999) considera que, se um grupo partilha dos mesmos códigos, assume uma identidade comum, que orienta procedimentos de regulação social que permitem ao grupo sua sobrevivência. Cada grupo cultural possui um sistema original de representações e de construções intelectuais que se relacionam com o sistema hierarquizado de preferências e valores. Isto confere à impressão de marcas culturais no território.

Os códigos culturais, assim como a cultura e a identidade, não são fixos e nem imutáveis. Brum Neto (2012) destaca o processo de desreterritorialização como influenciador nas transformações dos códigos culturais pelas adaptações à inovação e pela relação com a realidade nova proposta, ressaltando o 
processo de formação do sistema cultural, com mudanças e permanências. A autora apresenta a relação do processo de mudança e adaptação relacionado aos processos de imigração, especificamente a imigração alemã no estado gaúcho, foco de análise deste trabalho, a partir do qual se entende que, "adaptação e inovação emergem, geralmente, diante das dificuldades, como medida eficaz para resolução dos problemas. É como se fosse uma imposição natural para o ajuste cultural, para que o grupo social possa adaptar-se ao "novo" espaço, transformando-o em território" (BRUM NETO, 2012, p. 95).

Neste sentido, Brum Neto (2012) complementa que no processo de reterritorialização as transformações estão implícitas e a dinâmica socioespacial exerce forte influência sobre a construção e manutenção dos códigos culturais, originando transformações no intuito de (re)adaptar-se às novas territorialidades que se configuram.

Para esta pesquisa, delineia-se o código cultural da linguagem, que é usado como "guia" na análise empírica, para compreender, como a identidade territorial se manifesta na região central do Vale do Taquari. Cabe ressaltar que, com a análise de um elemento representativo da cultura (o código cultural da linguagem), não se tem a pretensão, tão pouco a condição, de apreender a cultura na sua totalidade conceitual e real.

Portanto, o código cultural que será apreendido na realidade local e regional é a língua (escrita e oralidade), a qual está diretamente vinculada ao ensino escolar e à reprodução do dialeto alemão no cotidiano dos imigrantes e seus descendentes.

\section{CÓDIGO CULTURAL DA LINGUAGEM, LÍNGUA E ORALIDADE}

A linguagem é um código cultural bastante amplo e inclusivo que contempla o sistema escrito e falado de uma língua. A linguagem engloba em seu interior outros códigos, como a música e o vestuário, como afirma Hall (2016, p. 37): "Enfim, qualquer som, palavra, imagem ou objeto que funcionem como signos, que sejam capazes de carregar e expressar sentido e estejam organizados com outros em um sistema, sob esta ótica, 'uma linguagem"'.

A língua é, então, um elemento crucial de qualquer cultura. Ela é fortemente afetada por outros aspectos de uma cultura. A linguagem é uma de suas características distintivas. Vale lembrar que pinturas, emblemas, gestos e tudo o que é reconhecido como "significando algo" também são linguagens. A cultura atribui significado a tudo, desde sons vocais deliberadamente articulados até seres, objetos e lugares (COSGROVE, 2007).

A linguagem é, simultaneamente, um produto da cultura, uma vez que uma língua em uso em uma sociedade reflete a cultura geral da população. Mas, a linguagem também é um dos elementos da cultura. Pode-se, ainda, tratar a linguagem como condição da cultura, por ser através dela que o indivíduo adquire a cultura do seu grupo, através da instrução formal e informal (CUCHE, 2002).

Neste contexto, a linguagem opera como um sistema representacional. Na linguagem, faz-se uso de signos e símbolos, que podem ser sonoros, escritos, imagens eletrônicas ou até objetos, para significar ou representar para outros indivíduos os conceitos, ideias e sentimentos do grupo social. "A representação pela linguagem é, portanto, essencial aos processos pelos quais os significados são produzidos" (HALL, 2016, p. 18).

Hall (2016) também considera que a linguagem é um dos principais "meios" pelos quais o sentido se vê elaborado e representado. $\mathrm{O}$ autor interpreta que a língua opera por meio de representação, isto é, as línguas são "sistemas de representação" que constroem significados e transmitem-nos. Assim, "a linguagem é uma prática significante" (HALL, 2016, p. 24).

A linguagem é tanto um código cultural material quanto imaterial. Ela é expressa visualmente através da escrita, permanecendo mais tempo na cultura de um povo. É também invisível quando transmitida pela oralidade, com grande poder de comunicação, mesmo correndo o risco de não se perpetuar por muito tempo e depender da valorização cultural do grupo social (CAETANO; BEZZI, 2011).

Diante do exposto, percebe-se a importância da linguagem para a compreensão e disseminação da cultura, uma vez que a linguagem de um grupo social é uma de suas características distintivas. Neste trabalho, que tem o processo migratório em seu bojo, buscou-se, na relação das distintas línguas e linguagens, compreender os significados construídos no decorrer do tempo pelos imigrantes alemães e seus descendentes na região central do Vale do Taquari. 


\section{A LÍNGUA ENQUANTO CÓDIGO DE PERTENCIMENTO ÉTNICO-CULTURAL: "É QUASE UMA SENHA PARA DIZER, NÓS SOMOS IGUAIS, É UM CARTÃO DE VISITA"}

Com base nas entrevistas realizadas nos municípios da região central do Vale do Taquari, consideraramse dois grupos distintos de entrevistados. Um formado por representantes do poder público local, mais especificamente das Secretarias de Cultura dos municípios, e, o outro, pelos membros da comunidade, composto majoritariamente de pessoas idosas, indicadas pelo primeiro grupo. Desta forma, a partir da aplicação do roteiro de entrevistas, obteve-se a apreensão das principais continuidades e descontinuidades ou rupturas relacionadas ao código cultural da linguagem relacionado com a cultura alemã na percepção dos entrevistados deste trabalho.

As falas foram reproduzidas por serem fundamentais na interpretação das manifestações culturais que são expressas na realidade regional, uma vez que elas emanam das/dos sujeitos que são os protagonistas da pesquisa.

As informações de campo estão impregnadas de historicidade, muitas vezes relacionadas diretamente ao processo de colonização alemã. Os processos de desreterritorialização também são identificados nas falas dos entrevistados. Assim, a interpretação da cultura e da construção da identidade territorial, por meio dos códigos culturais, revela apenas a apreensão parcial da realidade.

$\mathrm{Na}$ formação histórica dos municípios da região central do Vale do Taquari, a presença de outras etnias também foi evidenciada pelos entrevistados, com destaque para os indígenas, portugueses, africanos (sob a condição de escravos) e italianos. O processo de colonização do município de Arroio do Meio contou ainda com a participação de açorianos. Em Estrela foi ressaltada a presença de poloneses e espanhóis e, recentemente, a vinda de haitianos, estes últimos também presentes nos municípios de Poço das Antas e Lajeado.

No que se refere ao código cultural da linguagem, verifica-se que os dialetos derivados da língua alemã estão presentes em todos os municípios do recorte territorial em estudo. Nos municípios da região central do Vale do Taquari, percebe-se a variação linguística entre dois dialetos: o Hunsrückisch e o Plattdüüsch ou Vestfaliano.

O Plattdüüsch ou Vestfaliano, conhecido popularmente como Sapato de Pau, é falado principalmente entre os imigrantes oriundos da região da Vestfália no noroeste da Alemanha. No Vale do Taquari, os imigrantes e descendentes oriundos dessa região estabeleceram-se, principalmente, nos municípios de Teutônia, Westfália, Colinas e Imigrante. O dialeto Hunsrückisch é falado entre os imigrantes e descendentes provenientes da região do Hunsrück, no sudoeste da Alemanha, e prevalece nos municípios de Lajeado, Estrela, Marques de Souza, Arroio do Meio, Forquetinha, Poço das Antas e Santa Clara do Sul, situados na região central do Vale do Taquari.

Quanto ao dialeto Vestfaliano na cultura alemã, o entrevistado D, de Teutônia, relembra: "até os 15 anos eu usava o sapato de pau que foi trazido pelos imigrantes. [...] a língua chama de sapato de pau porque é a língua dos que usavam o sapato de pau, então foi abreviado isso para "língua sapato de pau"'. O entrevistado estabelece a relação entre o calçado e a forma como o dialeto é popularmente conhecido. Este dialeto está presente na região correspondente à antiga colônia de Teutônia, atualmente formada pelos municípios de Teutônia, Westfália e Colinas, que integram a região central do Vale do Taquari.

A língua dos espaços públicos é o português, enquanto a língua da esfera doméstica são os dialetos Hunsrückisch e o Plattdüüsch ou Vestfaliano. O entrevistado A, de Westfália, ressalta: "O que ajuda muito na Westfália é onde tem várias gerações na casa, aí se mantém, mas onde tem o casal sozinho com os filhos, aí acaba saindo fora".

A relação de convivência no ambiente familiar com até três gerações, ou seja, o convívio dos netos com avós, ajudou na preservação do dialeto alemão, esse que é considerado uma língua íntima, uma língua familiar. A coabitação de três gerações em uma mesma casa é denominada por Silva (2014) de "família tronco". Dessa forma, é traçada uma relação direta entre o hábito de falar alemão no cotidiano e o vínculo com pessoas mais idosas. O entrevistado I, de Poço das Antas, até expõe que: "alguns pais levam os filhos nas férias nos avós onde se comunicam em alemão".

Entretanto, nos espaços públicos, alguns entrevistados percebem uma diminuição no uso do idioma. Tal fato está relacionado com a "vergonha" que principalmente os mais jovens sentem de conversar usando o dialeto. Seyferth (2015) sinaliza que, no contexto urbano, o camponês, independentemente da etnia, é comumente qualificado de forma pejorativa.

O português é considerado a língua dos negócios. Por este viés, Seyferth (1990) ressalta que o bilinguismo é característico entre a maioria dos grupos de alemães e italianos, e que no cotidiano são 
utilizados dialetos que sofreram transformações pela influência da língua portuguesa. E como mencionado nas entrevistas, a língua comercial é o português, "o português, para eles, é a língua utilizada na esfera econômica ou no contato com estranhos" "(SEYFERTH, 1990, p. 93). Muitas famílias estabelecem a comunicação no ambiente familiar em alemão, apesar de as novas gerações terem, por vezes, um menor domínio dos dialetos. O Entrevistado G, do município de Forquetinha, aponta que a comunicação no dialeto não se restringe aos ambientes familiares, comenta que é comum em locais públicos, em festividades: "tu vai numa festa tu ouve quase só falar alemão, com exceção dos mais novos dessa geração, 10-12 anos, esses é uma completa mudança, inclusive os meus netos é difícil'.

Pode-se afirmar que, em todos os municípios em estudo, os entrevistados enfatizaram que há uma relação entre o uso mais frequente do dialeto e o meio rural. No município de Santa Clara do Sul, por exemplo, a diminuição do uso do idioma alemão está relacionada com a presença de empresas industriais que empregam mão de obra externa ${ }^{2}$ e priorizam a língua portuguesa. Outro exemplo é dado pelos municípios de Lajeado e de Estrela. Em Estrela, o uso da língua alemã diminuiu no decorrer do tempo, mas ainda é significativo e presente. Por outro lado, em Lajeado, que é o município que representa o polo industrial do Vale do Taquari, com altos índices de urbanização, há declínio no uso do dialeto alemão. Estes exemplos evidenciam que o dialeto alemão, principalmente entre as novas gerações, está sendo abandonado e, consequentemente, substituído pela língua portuguesa.

Nas unidades territoriais de Forquetinha e Westfália, muitas crianças ainda aprendem o alemão como primeiro idioma, e a língua portuguesa somente é incorporada a partir da inserção no ambiente escolar formal. Nos demais municípios, os entrevistados apontam para uma diminuição do uso do dialeto entre os mais jovens. Em Arroio do Meio, no cotidiano citadino, o português é mais evidente, mas ainda existe a incorporação de palavras em alemão no vocabulário do dia a dia.

No recorte territorial em estudo, o ensino da língua alemã está presente em sete municípios. Desses, cinco têm o idioma como caráter obrigatório, fazendo parte do currículo do ensino fundamental. Em dois municípios, o ensino do alemão é ofertado em caráter optativo, constando somente nas escolas privadas. E em dois municípios não há ensino da língua alemã. Estes últimos são os municípios de Poço das Antas, onde a lei orgânica prevê o incentivo ao alemão nas escolas, entretanto, na atualidade não está em prática o previsto na legislação. E em Santa Clara do Sul, onde a ausência do ensino do idioma é atribuída à dificuldade em realizar concursos para seleção de professores de alemão, uma vez que na última edição não houve candidatos habilitados.

O município de Estrela atualmente conta com ensino da língua alemã apenas em escolas privadas, de caráter optativo, mas está com projeto para retomar o ensino nas escolas públicas, que, entretanto, não está em funcionamento. Lajeado, outro município em que o ensino de alemão é ofertado somente nas escolas privadas, não elencou nenhum projeto que estivesse sendo realizado para a valorização da língua alemã no ensino público.

Dentre os municípios que ofertam o ensino da língua alemã, destaca-se Forquetinha, que, além do ensino da disciplina até o $9^{\circ}$ ano, também oferece no turno inverso um curso preparatório para a prova do Instituto Goethe ${ }^{3}$. E em Teutônia, as aulas de alemão são oferecidas no final da tarde, para possibilitar a participação da comunidade de forma geral, além da oferta no ensino fundamental de caráter obrigatório. Em Arroio do Meio, o ensino da língua alemã é ofertado apenas na escola que se localiza no distrito mais afastado da cidade, no meio rural, uma vez que nas escolas de bairros urbanos há uma maior diversidade étnica.

Destaca-se, também, que em Arroio do Meio existem duas leis aprovadas que viabilizam o intercâmbio cultural de jovens de 16 a 23 anos do município com a cidade de Boppard, na Alemanha. As leis municipais 2.982, de 2011, e 3.335, de 2014, firmam a parceria entre Arroio do Meio e Boppard como cidades coirmãs. Essa parceria tem como objetivo principal o intercâmbio de jovens estudantes entre as duas cidades. De forma anual e alternada, grupos de estudantes fazem visitas programadas para a cidade-irmã. Trata-se de um projeto de educação complementar, extracurricular, que está ao alcance dos jovens, de acordo com a legislação previamente aprovada pelo Poder Legislativo do município, o qual dispõe de recursos para fomentar as ações estabelecidas no projeto.

\footnotetext{
1 Pessoas não pertencentes à descendência alemã.

2 No município as empresas calçadistas se destacam, e, pela grande demanda por mão de obra, são absorvidas pessoas de todo o Vale do Taquari, havendo predomínio do português na comunicação íntima cotidiana.

${ }^{3}$ O Goethe-Institut é o instituto cultural de âmbito internacional da República Federal da Alemanha. Com objetivo de promover o conhecimento da língua alemã no exterior e o intercâmbio cultural internacional. As provas do instituto foram concebidas para atestar conhecimentos de alemão como língua estrangeira e de alemão como segunda língua (GOETHE, 2018). 
Os representantes da Secretaria de Educação e Cultura de Arroio do Meio também apontaram que a intenção é ampliar o alcance desta parceria, envolvendo professores, agricultores e, inclusive, apoiando logisticamente o intercâmbio mútuo de cidadãos de qualquer idade. O entrevistado $F$, de Arroio do Meio, também apresentava domínio do projeto e expôs as perspectivas de ampliação do programa como uma iniciativa de desenvolvimento regional.

\begin{abstract}
A nossa iniciativa aqui, com uma cidade-irmã na Alemanha, nasceu dessa vontade de manter os vínculos com a pátria dos imigrantes, nossos antepassados. Ela nasce com a vontade de manter estes vínculos. Ela imediatamente ampliou o seu foco para uma finalidade mais pragmática também, e não apenas o histórico, menos ainda o saudosista, ela ampliou o seu foco para ser alguma coisa importante para o desenvolvimento do município. E a atividade que existe até hoje, que pode ser ampliada, e existem iniciativas neste sentido de ampliar ela mais ainda.
\end{abstract}

O município de Colinas, segundo informações da Secretaria Municipal de Educação, Cultura, Turismo e Desporto, possui um projeto de resgate de cartas antigas da comunidade (escritas em alemão, português ou em outra língua), no intuito de criar um acervo histórico e produzir um livro retratando a história da época da imigração e da colonização alemã do município. As cartas recebidas são digitalizadas, identificadas e devolvidas à comunidade.

No Plano Diretor do município de Westfália estão elencadas algumas características referentes à cultura alemã e que fazem parte do patrimônio imaterial do município: o sapato de pau, o hino oficial, o dialeto Plattdüüsch, o grupo de danças folclóricas alemãs Westfälische Tanzgruppe, o coral municipal, o Kerb, o bolinho de batata, o muro taipa, a flor símbolo rosa rugosa e a bandeira oficial (WESTFÁLIA, 2017).

Além do Plano Diretor, no mesmo município, existe a Lei 1.302, de 2016, que estabelece o Plattdüütsch (Sapato de Pau) como língua cooficial. A partir desta oficialização, a lei prevê também o incentivo, pelo uso do dialeto, de saberes tradicionais relacionados à música, ao canto, ao teatro, às danças, aos jogos, entre outros (WESTFÁLIA, 2017). Além desta política, no município existe o grupo "Amigos do Sapato de Pau", que se dedica à construção de um dicionário na língua Sapato de Pau. Este grupo está sob a coordenação do professor Lucildo Ahlert e se reúne mensalmente, desde 2013, para compartilhar pesquisas e avançar na construção do dicionário, o qual servirá de referência para a língua e para a valorização cultural no município.

No dia 04 de setembro de 2019, ocorreu o lançamento do Dicionário da Língua Westfaliana. A secretaria de Cultura e Educação de Westfália ressalta a importância do dialeto estar registrado em um dicionário, disseminando seu uso e valorizando a cultura alemã no município.

\begin{abstract}
Antes, ele era visto até de forma pejorativa. Agora, pelo contrário, se vê como uma valorização da cultura local. Haverá doações do dicionário para as escolas e famílias interessadas. Entretanto, elas deverão atender a uma série de critérios que serão divulgados pela administração para sua obtenção. Também será disponibilizado um exemplar na Biblioteca Municipal (DICIONÁRIO, 2019, p. 1).
\end{abstract}

Nas entrevistas com os informantes qualificados, quando a pauta foi o código cultural da linguagem, percebeu-se, de modo geral, uma reflexão histórica associada com a Primeira e Segunda Guerras Mundiais e o período do Estado Novo no Brasil. Nestes períodos, um sentimento de medo da repressão se difundiu entre os descendentes de imigrantes alemães. Nos relatos, os entrevistados contaram histórias do medo vivido pelos antepassados no período, quando as famílias destruíam ou escondiam os documentos, livros, bíblias, fotos, qualquer pertence que pudesse apontar sua relação com a Alemanha.

Roche (1969) compreende que foi justamente a partir de $1914^{4}$ que houve a "liquidação da colonização alemã" ao Brasil, associada diretamente com as duas Guerras Mundiais, nas quais Brasil e Alemanha lutaram em lados opostos. O autor constata também que os colonos, ao mesmo tempo em que dependiam do governo brasileiro, mantinham-se com laços culturais que os ligavam à Alemanha.

$\mathrm{Na}$ associação da língua com o ensino, os entrevistados lembram que nas escolas fundadas pelos imigrantes, nas escolas comunitárias, até 1937, os conteúdos eram ensinados em alemão. O entrevistado F, de Arroio do Meio, explana que: "os primeiros professores de língua portuguesa eram amadores, o que melhor sabia ler iria ministrar, meu pai foi um deles, eles entre si tinham dificuldade de se comunicar em português". Nesta perspectiva, o entrevistado C, de Lajeado também comenta:

${ }^{4}$ Ano em que inicia a Primeira Guerra Mundial $(1914-1918)$.
$\begin{array}{llllll}\text { Caminhos de Geografia } & \text { Uberlândia-MG } & \text { v. } 21, \text { n. } 77 & \text { Out/2020 } & \text { p. 180-192 } & \text { Página } 187\end{array}$


[...] a escola era a joia preciosa da comunidade - se não tinha professor, alguém entre os imigrantes assumia esta tarefa para ensinar os filhos. Eu tenho isso muito presente na minha infância, porque meus pais participavam da comunidade escolar, era muito importante, era uma referência na comunidade, e isso se manteve, apesar de todos os percalços políticos desta escola comunitária.

Dahmer (2015) afirma que muitas vezes as empresas colonizadoras exigiam que no grupo de imigrantes viesse um professor, dado que a instrução era considerada fundamental para os imigrantes, que logo após se instalarem nas matas já iniciavam a construção das primeiras escolas comunitárias. $\mathrm{E}$, quando não se tinha um professor no grupo, era eleita a pessoa mais instruída para desenvolver este papel.

Segundo Knob e Knob (1998), a partir de 1938, as escolas teuto-brasileiras foram oficializadas e não poderiam mais ministrar aulas em alemão, sendo introduzidos os primeiros professores bilíngues, os quais geralmente eram pessoas da comunidade, "amadores" da língua, isto é, não tinham educação formal mas eram autodidatas, para instruir os alunos. Nesse período, ocorreu um rompimento na vida em sociedade dos colonos alemães, uma vez que a sociabilidade na escola, na igreja e na sociedade recreativa transcorria com o uso do dialeto alemão. Entretanto, com a proibição do uso do alemão em atos públicos, os colonos enfrentaram dificuldades de comunicação, pois ainda não dominavam o idioma português.

Com a proibição do uso do idioma alemão no Brasil, no período da Segunda Guerra Mundial, muitas escolas das comunidades rurais foram fechadas, pelo fato de os professores serem considerados suspeitos de traição à pátria ${ }^{5}$. As reuniões das sociedades, os cultos, as missas que ocorriam no idioma alemão tiveram que passar a ser realizadas em português (FUNDAÇÃO OSWALDO CARLOS VAN LEEUWEN, 2003).

Menasche e Schmitz (2007) enfatizam que no período correspondente à Segunda Guerra Mundial houve um hiato nas atividades de sociedades de canto e nas demais expressões da organização comunitária. Ainda sobre o período de nacionalização, o entrevistado I, de Poço das Antas explica:

\begin{abstract}
Dentro da escola no período de guerras não se pronunciava uma palavra em alemão, o professor se esforçava, as crianças falavam o mínimo, pouca conversação. Usar o alemão era perigosíssimo. Intervalo falava alemão - era aplicado castigo - , perdia direito ao intervalo, onde o professor zelava sobre isso. [...] Passava para o lado de fora da escola, no fim da aula, não falava uma palavra em português.
\end{abstract}

O entrevistado continua a reflexão de que a introdução do português nas escolas não levou ao abandono da língua alemã: "a escola não resolveu o problema, a exposição, o contato da vida fora da escola era tudo em alemão [...] eram raras as pessoas que soubessem se defender em português".

Outro fator histórico, relembrado pelos entrevistados, foi 0 isolamento geográfico. Neste sentido, o entrevistado $\mathrm{F}$ de Arroio do Meio expõe: "A demora em abandonar o alemão e praticar o português foi devido ao isolamento, social, cultural, econômico. Essa região aqui, como outras, se encontraram. Entre si não tinha como aprender a língua pátria". Os escritos de Seyferth (1988) corroboram com a constatação do entrevistado, apontando que os imigrantes alemães, diferentemente das outras etnias que imigraram para o Brasil até a chegada destes, concentraram-se em áreas "compactas e homogêneas" no Rio Grande do Sul.

Diante desse isolamento nas áreas de matas, a pouca exposição dos descendentes de imigrantes a ambientes de fala lusa foi o que os levou a continuar falando alemão. Waibel (1979) também constatou que estes imigrantes formaram "comunidades próprias" tanto cultural como economicamente.

Os meios de comunicação como jornais, rádio e televisão também foram lembrados pelos entrevistados. Os jornais e as revistas escritos em alemão, até a Segunda Guerra Mundial, eram de circulação comum entre os imigrantes e os descendentes que os assinavam. Após este período, tem-se a retração dessa circulação, pois, a partir da proibição do uso da língua alemã, ocorre o fechamento das bibliotecas comunitárias que existiam nas comunidades rurais, e, consequentemente, a diminuição no hábito da leitura entre essas pessoas.

Com o advento da tecnologia, o rádio passou a ocupar as noites, intercalando programação em português e em alemão. A televisão é apontada como protagonista na disseminação do português entre os

${ }^{5}$ Fachel (2002, p. 171) afirma que, assim como a religião, a educação também era uma área fiscalizada pela polícia no período do Estado Novo. "O conceito de segurança política do Estado, num clima de guerra, em que o governo podia divulgar e censurar tudo, permitiu a construção de sofismas. O resultado desastroso da nacionalização das escolas seria consequência da reação nazista dos professores. [...] Não há dúvida de em algumas escolas haver professores nazistas, mas a generalização não é correta".

$\begin{array}{lllll}\text { Caminhos de Geografia } & \text { Uberlândia-MG } & \text { v. 21, n. } 77 & \text { Out/2020 } & \text { p. 180-192 Página } 188\end{array}$


descendentes de imigrantes alemães. Neste sentido, Menasche e Schmitz (2007, p. 89) expõem que dentro de casa "o alemão permanecia sendo o idioma vivenciado no cotidiano dos colonos. Até a chegada da televisão, era comum que as crianças apenas viessem a ter contato com o português quando iniciadas na escola".

Outro fator apontado pelos entrevistados como responsável pela disseminação do português nas comunidades foi o intercâmbio entre sociedades esportivas. A partir de campeonatos esportivos, passaram a ocorrer encontros de distintas comunidades com hábitos linguísticos diferentes, e para que houvesse comunicação se deveria ter um mínimo de entendimento da língua portuguesa. $O$ entrevistado J, de Santa Clara do Sul, estabelece essa relação: "clubes de diferentes localidades se encontravam, e isso provocou uma melhora mais sensível, teve uma influência mais forte que o rádio para as pessoas se comunicarem em português".

Na contemporaneidade, nos municípios da região central do Vale do Taquari, ainda está presente, em algumas lojas comerciais, um funcionário que entende e fala alemão, principalmente naquelas que têm uma relação maior com a colônia, como em estabelecimentos agropecuários, lojas de vestuário, entre outras. Tal situação ocorre devido ao fato de algumas pessoas idosas que frequentam esses locais não dominarem o português ou apresentarem dificuldade de comunicação neste idioma.

$\mathrm{O}$ entrevistado $\mathrm{H}$, de Estrela, comenta acerca do hibridismo linguístico do alemão e do português na comunicação do cotidiano:

[...] hoje é muito falado [alemão], agora já mais misturado com o português. Em meio de uma conversa uma hora se fala em alemão e outro momento em português. Os locutores da conversa podem fazer perguntas em alemão e receber a resposta em português ou vice-versa. Muitas das crianças no interior aprendem o português de fato apenas quando vão para a escola.

Atualmente, a escolarização das crianças, a partir da educação infantil, é apontada como fator que dificulta o ensino do alemão em casa. Antigamente, entre muitas famílias, era comum o ensino do alemão como primeira língua, e a aprendizagem do português ocorria apenas com o contato na escola, quando as crianças tinham entre 6 e 7 anos de idade.

É importante enfatizar que o entrevistado A, de Westfália, estabelece uma crítica reflexiva sobre o ensino do alemão nas escolas. Ele expõe que o alemão formal não compreende o dialeto aprendido em casa.

[...] eu percebi o quanto se perde do conhecimento existente do ensino de língua inglesa e alemã. Tu tem em casa um pessoal que fala uma coisa, e tu na escola ignora completamente isso, e pior quando a pessoa tenta fazer um esforço em alemão e fala uma palavra, aí ele cai naquela palavra que fala em casa, a professora diz que não está correto e ele tem um bloqueio, "bom, então", ele diz, "estou falando errado"; se ela pudesse dizer, "o que tu tá dizendo é Hunsrückisch ou Plattdüüsch , é isso, a palavra é assim, mas transformando a palavra assim tu vai estar no inglês ou no alemão", a pessoa ia fazer um esforço para fazer essa relação, e não precisa esquecer o que sabe.

Neste sentido, a secretária municipal de Educação de Westfália, em entrevista ao Jornal "A Hora" após o lançamento do dicionário, afirma que ele terá reflexo no ensino, pois o dialeto poderá ser trabalhado com os alunos futuramente. A secretária ressalta:

[...] sem dúvidas, o dicionário viabiliza o ensino e a aprendizagem desse dialeto, fazendo com que essa cultura não se perca no município. Mas temos um longo caminho pela frente. A parte gramatical precisa ser trabalhada e as regras, como em qualquer língua, precisam ser construídas para serem ensinadas (DICIONÁRIO, 2019, p. 1).

$\mathrm{Na}$ atualidade, a comunicação nos dialetos no cotidiano faz parte das vivências. O entrevistado $\mathrm{C}$, de Lajeado, interpreta de forma saudosista essa relação: "Pessoas de mais idade, falam em alemão, em casa, na rua, se sabem que alguém fala, cumprimentam em alemão, acho que é uma questão de saudosismo, lembra infância, lembra família, tem uma nostalgia em cima disso".

Além disso, este entrevistado identifica o alemão como uma língua de aproximação e, ao mesmo tempo, de diferenciação em relação ao outro, como é possível observar no relato de sua experiência,

É uma coisa da língua, várias vezes eu experimentei isso, me apresentava como jornalista, as pessoas tinham um pouco dificuldade de falar o português, e aí falava uma palavra em alemão no meio para eles saberem que eu falava alemão, e uma expressão comum usada, era: "das ist einer von unseren" [este é um dos nossos]. Essa frase é quase uma senha para dizer, nós somos iguais, é um cartão de visita. 
No intuito de traçar um paralelo sobre alteridade, recorre-se a Castells (1999), quem expõe que de alguma forma se estabelece a distinção entre o eu e o outro, o nós e o eles. Aqui a linguagem se configura como uma fronteira, diferenciando o pertencimento a um grupo ou não.

Cabe destacar que as entrevistas foram realizadas em português e quando percebia-se uma dificuldade de comunicação por parte do entrevistado, fazia-se uso do dialeto, uma vez que a uma vez que a pesquisadora/entrevistadora é descendente de alemão e fala o dialeto. Salienta-se que esse conhecimento foi importante, principalmente com os entrevistados idosos, que só se comunicam no dialeto alemão.

Por mais difundido que possa ser o alemão no cotidiano, essa presença se restringe à língua falada. Não foi identificado domínio por parte da comunidade, em sua grande maioria, na escrita em alemão.

O Informante G, de Forquetinha, comenta sobre isso: "percebe-se um medo de errar na escrita, quando o pessoal recebe uma correspondência da Alemanha e tem medo de escrever com receio do erro. Isso é uma pena. Dificilmente respondem".

Em alguns municípios da região central do Vale do Taquari são visíveis as expressões de traduções para o alemão e para os dialetos em placas de identificação e sinalização, em mapas, folders e guias. Estas identificações podem ser relacionadas com as rotas turísticas, uma vez que são direcionadas aos visitantes.

Desta forma, o que se percebe na região do Vale do Taquari é que ainda há uma expressividade do uso dos dialetos alemães no cotidiano, principalmente nos ambientes familiares, estando mais presente na relação com as pessoas idosas e nas áreas rurais, com destaque nos municípios menos urbanizados. E a relação estabelecida entre o dialeto alemão e a educação informal é construída a partir do fato de o alemão ser a língua materna. Neste sentido o entrevistado E, de Colinas, expõe: "[...] surpreende, gente, eu mesmo sei falar alemão, não porque estudei em escola alemã, mas porque foi minha língua materna. Eu acho que é muito forte a participação da língua alemã".

Quanto ao uso dos diferentes dialetos alemães, na atualidade, na região central do Vale do Taquari, ainda são percebidos reflexos da política proibitiva do uso do idioma (nos períodos de Guerras e na campanha de nacionalização do Estado Novo), quando ele foi estigmatizado, e, ainda hoje, identificam-se reflexos de memórias deste período.

De acordo com Horst (2014), a região central do Vale do Taquari se configura como uma região "plurilíngue", em que, além do português, distintos dialetos ainda são utilizados na atualidade. Alguns fatores são elencados como responsáveis pela diminuição da comunicação no dialeto alemão no cotidiano, entre eles, a ampliação dos meios de comunicação e o ensino formal mais cedo entre as crianças.

\section{CONSIDERAÇÕES FINAIS}

O código cultural da linguagem analisado, especificamente a língua alemã, na sua vertente formal ensinada nas escolas, com a prática da escrita ou pelos dialetos reproduzidos no cotidiano, principalmente pela linguagem oral, é responsável pela construção e pela transmissão de significados da cultura. Isso ocorre seja por intermédio da tradição oral, que transmite o saber-fazer ao longo das gerações, seja pela escrita, que permite que receitas culinárias tradicionais sejam repassadas, correspondências sejam trocadas, dentre outros inúmeros exemplos que poderiam ser elencados.

Quanto à língua alemã, seu ensino formal não está presente em todos os municípios e, nos casos em que é registrado, resguarda a distinção do caráter optativo ou obrigatório no currículo escolar. É importante assinalar o papel fundamental das iniciativas do poder público municipal, as quais auxiliam na preservação dos códigos culturais e demais manifestações vinculadas à presença da cultura alemã nos municípios que integram o Vale do Taquari. Entretanto, todos de alguma forma manifestaram a presença de projetos de políticas públicas visando ao resgate do uso da língua. Salienta-se que o ensino do alemão, além de estar vinculado à formação étnica dos municípios, também objetiva a inserção futura, principalmente dos jovens, no mundo globalizado. Entretanto, na comunidade é percebido um distanciamento da língua ensinada nas escolas em relação aos dialetos praticados no cotidiano.

O processo de nacionalização do ensino, no período do Estado Novo, teve a pretensão de disseminar a identidade nacional por intermédio de padrões de alfabetização, com uso de uma única língua, visando à criação de uma cultura homogênea. Entretanto, o que se percebeu na realidade regional foi que esta 
tentativa de uniformização cultural gerou um processo de alteridade, ressaltada entre os imigrantes e os descendentes de alemães, ao mesmo tempo em que a sua identidade cultural teve como referência a origem étnica, calcada na tradição.

No que tange à linguagem, há uma expressividade no uso dos dialetos alemães no cotidiano, principalmente nos ambientes familiares, sendo mais presente na relação com as pessoas idosas e nas áreas rurais, com destaque nos municípios menos urbanizados. Essa presença se restringe à língua falada, uma vez que não foi identificado domínio, por parte da comunidade, da escrita em alemão. Os dialetos presentes na região apresentam duas variações que configuram distintas territorialidades.

A transmissão de significados da cultura ocorre com o uso da linguagem, principalmente da oralidade, pois o saber-fazer é transmitido entre as gerações por intermédio dela. A língua, além de ser um veículo de aproximação entre seus pares, também se configura como um elemento diferenciador, configurando-se como uma fronteira linguística, diferenciando o pertencimento a um grupo ou não. Ao mesmo tempo em que une, também separa.

\section{REFERÊNCIAS}

BRUM NETO, Helena. Os Territórios da Imigração Alemã e Italiana do Rio Grande Do Sul. 318 f. Tese (Doutorado em Geografia) Universidade Estadual Paulista, Presidente Prudente, 2012.

BRUM NETO, Helena. Regiões Culturais: a construção de identidades culturais no Rio Grande do Sul e sua manifestação na paisagem gaúcha. 2007, 328f. Dissertação (Mestrado em Geografia) Universidade Federal de Santa Maria, Santa Maria, 2007. https://doi.org/10.1590/S1982-45132008000200009

CAETANO, Jéssica N.; BEZZI, Meri L. Reflexões na geografia cultural: a materialidade e a imaterialidade da cultura. In: Sociedade \& Natureza, Uberlândia, ano 23, n.3, p. 453-466, set./dez. 2011. https://doi.org/10.1590/S1982-45132011000300007

CASTELLS, Manuel. O Poder da Identidade. Tradução Klauss Brandini Gerherdt. V.2 - A era da informação: economia, sociedade e cultura. 6.ed. São Paulo: Paz e Terra, 1999.

CLAVAL, Paul. A geografia cultural. 4. ed. Revista. Tradução: Luís Fugazzola Pimenta e Margareth de Castro Afecche Pimenta. Florianópolis: Ed. Da UFSC, 2014. (1999 - 1ª edição).

CORRÊA, Roberto L.; ROSENDAHL, Zeny. Geografia cultural: apresentando uma antologia. In: CORRÊA, Roberto L.; ROSENDAHL, Zeny. (Orgs) Geografia Cultural: Uma antologia. Vol. 1 Rio de Janeiro: EdUERJ, 2012. P. 7-14. https://doi.org/10.7476/9788575114384

COSGROVE, Denis E. Em Direção a uma Geografia Cultural Radical: problemas da teoria. In: CORRÊA, Roberto L.; ROSENDAHL, Zeny (Orgs). Introdução à Geografia Cultural. 2 ed. Rio de Janeiro: Bertrand Brasil, 2007, p.103-34.

COSGROVE, Denis E.; JACKSON, Peter. Novos rumos da geografia cultural. In: CORREA, Roberto Lobato; ROSENDAHL, Zeny (orgs.) Introdução à Geografia Cultural. Rio de Janeiro: Bertrand Brasil, 2003. pp. 135-46.

CUCHE, Denys. A noção de cultura nas ciências sociais. Tradução: Viviane Ribeiro. 2.ed. Bauru: EDUSC, 2002. (1999 - 1ª edição).

DAHMER, Elio. A Imigração Alemã: por que os alemães colonizaram o Brasil? A história da Colônia de Teutônia, Linha Frank e Linha Schmidt. Lajeado: Ed. UNIVATES, 2015.

DICIONÁRIO eterniza dialeto. Jornal A Hora. Lajeado, 04 set. 2019. p. 1. Disponível em: <https://www.jornalahora.com.br/2019/09/04/dicionario-eterniza-dialeto/>. Acesso em: 28 nov. 2019.

FACHEL, José P. G. As violências contra alemães e seus descendentes: durante a Segunda Guerra Mundial, em Pelotas e São Lourenço do Sul. Pelotas: Ed. UFPel, 2002.

FUNDAÇÃO Oswaldo Carlos van Leeuwen. Sociedades de canto no Vale do Taquari: história e tradição. Lajeado: Fundação..., 2003.

GOETHE Institut. Tarefas e Objetivos, 2018. Disponível em: $<$ https://www.goethe.de/ins/br/pt/ueb/auf.html>. Acesso em: 13 abr. 2018.

HALL, Stuart. A identidade cultural na pós-modernidade. Traduzido por Tomaz Tadeu da Silva e Guacira Lopes Louro. 2 ed. Rio de Janeiro: DP\&A, 1999.

$\begin{array}{lllll}\text { Caminhos de Geografia } & \text { Uberlândia-MG } & \text { v. 21, n. } 77 & \text { Out/2020 } & \text { p. 180-192 Página } 191\end{array}$


HALL, Stuart. A identidade cultural na pós-modernidade. Trad. Tomaz Tadeu da Silva e Guacira Lopes Louro. 8. ed. Rio de Janeiro: DP\&A, 2003.

HALL, Stuart. Cultura e Representação. Tradução Daniel Miranda e William Oliveira. Rio de Janeiro: PUC-Rio: Apicuri, 2016.

HASENACK, Henrich; WEBER, Eliseu. Base Cartográfica Vetorial Contínua do Rio Grande do Sul. Escala 1:50.000. Porto Alegre: UFRGS, Centro de Ecologia, 2010.

HORST, Aline. Variação e Contatos Linguísticos do Vestfaliano Rio-Grandense Falado no Vale do Taquari. 2014. 230 f. Dissertação (Mestrado) Universidade Federal do Rio Grande do Sul, Instituto de Letras, Programa de Pós-Graduação em Letras, Porto Alegre, 2014.

IBGE - Instituto Brasileiro de Geografia e Estatística. Base Cartográfica Vetorial Contínua do Brasil ao milionésimo - BCIM. Rio de Janeiro: IBGE, 2010.

KNOB, Frei Pedro; KNOB, Darcísio. Poço das Antas: Primeiro lugar no ranking de alfabetização. Porto Alegre: Evangraf, 1998.

MATOS, Patrícia Francisca de; PESSÔA, Vera Lúcia Salazar. Observação e entrevista: construção de dados para a pesquisa qualitativa em Geografia agrária. In: RAMIRES, Julio Cesar de Lima; PESSÔA, Vera Lúcia Salazar (Orgs.). Geografia e pesquisa qualitativa: nas trilhas da investigação. Uberlândia: Assis, 2009. p. 279-291.

MENASCHE, Renata; SCHMITZ Leila C. Agricultores de origem alemã, trabalo e vida: saberes e práticas em mudança em uma comunidade rural gaúcha. In: MENASCHE, Renata (Org). A agricultura familiar à mesa: saberes e práticas da alimentação no Vale do Taquari. Porto Alegre: UFRGS, 2007. p.78-99. https://doi.org/10.1590/S1415-52732008000500013

ROCHE, Jean. A Colonização Alemã e o Rio Grande do Sul. Porto Alegre: Globo, V.1, 1969.

SEMA - SECRETARIA DO AMBIENTE E DESENVOLVIMENTO SUSTENTÁVEL (RS): Base Cartográfica do Estado do rio Grande do Sul. Escala 1:25.000. Porto Alegre: SEMA, Divisão cartográfica, 2018.

SEYFERTH, Giralda. A Colonização Alemã em Santa Catarina: hábitos alimentares e etnicidade. In: MENASCHE, Renata (Org.). Saberes e Sabores da Colônia: Alimentação e cultura como abordagem para o estudo do rural. Porto Alegre: UFRGS, 2015. p.133-160.

SEYFERTH, Giralda. A Colonização Alemã no Vale do Itajaí-Mirim. Porto Alegre: Movimento, 1974.

SEYFERTH, Giralda. Imigração e colonização alemã no Brasil: uma revisão bibliográfica. Boletim Informativo e bibliográfico de Ciências Sociais, n. 25, p. 3-55, 1988.

SEYFERTH, Giralda. Imigração e Cultura no Brasil. Brasília: EdUNB, 1990.

SILVA, Juniele M.; MENDES, Estevane de P. P. Abordagem qualitativa e Geografia: pesquisa documental, entrevista e observação. In: MARAFON, Glaucio José et al. (Orgs.). Pesquisa qualitativa em Geografia: reflexões teórico-conceituais e aplicadas. Rio de Janeiro: EdUERJ, 2013. p. 207-221. https://doi.org/10.7476/9788575114438.0013

WAGNER, Philip L.; MIKESELL, Marvin W. Os temas da Geografia Cultural. In: CORREA, Roberto Lobato; ROSENDAHL, Zeny (orgs.) Introdução à Geografia Cultural. Rio de Janeiro: Bertrand Brasil, 2003. pp. 27-61.

WAIBEL, Leo. Capítulos de Geografia Tropical e do Brasil. 2 ed. Rio de Janeiro: IBGE, 1979.

WESTFÁLIA. Lei № 1.441, de 22 de dezembro de 2017. Institui o Plano Diretor Participativo Sustentável Municipal - PDPS do município de Westfália e dá outras providências. Westfália: Gabinete do Prefeito Municipal, 2017.

Recebido em: 10/02/2019

Aceito para publicação em: 06/08/2020 